\title{
O EFEITO EXTRAJURISDICIONAL DOS PRECEDENTES NO SISTEMA PROCESSUAL CIVIL BRASILEIRO
}

\author{
THE EXTRAJURISDICTIONAL EFFECT OF PRECEDENTS \\ ON BRAZILIAN CIVIL PROCEDURAL SYSTEM
}

\author{
JEAN CARLOS DIAS ${ }^{1}$ \\ SAMIRA VIANA SILVA ${ }^{2}$
}

\section{RESUMO}

Este trabalho teve por objetivo analisar a relação entre precedentes judiciais vinculantes e arbitragem, agências reguladoras e órgãos parajurisdicionais, a fim de verificar se em ambientes não jurisdicionais os precedentes também exercem efeito vinculante. Através de pesquisa bibliográfica, foi possível verificar que, em que pese a grande divergência doutrinária acerca do assunto, o entendimento mais adequado é aquele segundo o qual os precedentes vinculam a administração pública e a arbitragem, em observância de princípios constitucionais que são pedras angulares no ordenamento jurídico brasileiro, como segurança jurídica e isonomia, bem como para que haja uma coerência sistêmica entre os entendimentos firmados sobre o mesmo direito tanto no âmbito do Judiciário quanto em ambientes extrajurisdicionais. Entretanto, ainda é necessário que o sistema de precedentes brasileiro passe por adaptações a fim de que este entendimento se fortaleça.

Palavras-chave: Precedentes Judiciais. Extrajurisdicional. Efeito Vinculante.

\section{ABSTRACT}

The main objective of this work was to analyze the relation between judicial precedents and arbitration, regulatory agencies and parajursdictional bodies, in order to verify if in these non-jurisdictional environ-

1 Doutor em Direitos Fundamentais e Relações Sociais pela pela Universidade Federal do Pará (2006). Mestre em Instituições Jurídico-Políticas pela Universidade Federal do Pará (2002). Pós-graduado em Direito Civil e Processo Civil pela Unesa Rio de Janeiro (2000). Graduado em Direito pela Universidade Federal do Pará (1993). Atualmente é Advogado, Sócio-Sênior de Bastos \& Dias s/s, escritório especializado em Direito Empresarial. Professor de Teoria do Direito, Direito Processual Civil, Teoria Geral do Processo e Direito Econômico nos cursos de graduação e pós-graduação do Centro Universitário do Pará- CESUPA onde também coordena o Programa de Pós-graduação em Direito. Professor convidado da Escola Superior da Magistratura do estado do Pará, do Centro de Formação do Ministério Público do Estado do Pará, da Escola Superior da Advocacia, da Escola Judiciária do Tribunal de Justiça do Amapá, da Escola Judiciária do Tribunal Regional do Trabalho da 8a. Região. É membro do Instituto dos Advogados do Pará, da Associação Norte-Nodeste de Professores de Processo, do Instituto Brasileiro da Política e Direito da Informática, da Fundação Brasileira de Direito Econômico. Integra diversos Conselhos Editorais de revistas jurídicas. Membro de bancas de Concursos Públicos. Tem participado como Conferencista e Professor em diversos congressos, cursos de pós-graduação, seminários e encontros jurídicos em vários Estados brasileiros. É autor de vários livros e artigos publicados nacionalmente. ORCID iD: https://orcid.org/0000-0002-8372-9758. E-mail: jean@bastosedias.com

2 Graduada em Direito pelo Centro Universitário do Estado do Pará (CESUPA). Pós-graduanda em Direito Processual Civil pelo CESUPA. Advogada. E-mail: samiraviana7@gmail.com. 
ments the precedents have binding effect. Through a bibliographical research, was possible to verify that, in spite of the great doctrinal divergence about this subject, the more appropriate understanding is that precedents bind the public administration e the arbitration, due to principles that are corner stones in the brazilian legal system, such as legal certainty and isonomy, as well as for there to be systemic coherence between the understandings made about the same right, both within the Judiciary and in extrajurisdictional environments. However, it's still necessary that the brazilian system of precedents undergo some adaptations, that this understanding may be strengthened.

Key-words: Judicial Precedent. Extrajurisdictional. Binding Effect.

\section{INTRODUÇÃO}

O sistema de precedentes estabelecido no nosso atual Código de Processo Civil assumiu, como a tradição já consolidada na experiência internacional, a vinculatividade vertical e horizontal. Isso significa que, instituído o precedente, nos moldes estabelecidos pela legislação, a obrigatoriedade de atendimento é exigível tanto em relação aos juízes vinculados a um determinado Tribunal como também o é em relação à própria Corte que o editou.

Ainda que, pontualmente, se discorde do caráter obrigatório dos precedentes, de fato a introdução desse modelo em nosso sistema jurídico não teria qualquer razão de ser senão assegurar a uniformidade de decisões judiciárias. A uniformidade, por sua vez, pressupõe a inexistência de faculdade na aplicação dos padrões normativos já fixados pelo sistema de produção dos precedentes entendido como uma fonte legítima. Porquanto se possa avançar na refutação de todas as teses centrais desse argumento, não trataremos do tema aqui.

É certo que a uniformização, por parte dos Tribunais, de teses jurídicas por meio de precedentes judiciais impacta diretamente em questões socialmente relevantes, o que acaba ocasionando uma regulação e controle jurídicos dessas questões, em especial no que tange aos serviços públicos. Dessarte, se um precedente judicial gera esses efeitos em relação a aspectos relevantes de um determinado direito, este precedente seria de observância obrigatória em ambientes extrajurisdicionais nos quais haja conflito acerca deste mesmo direito?

O ponto em questão é investigar até que ponto é possível sustentar a obrigatoriedade de adoção dos precedentes em ambientes não jurisdicionais, ou dito de outro modo, o que se perquire é a possibilidade de um efeito vinculativo extrajurisdicional. Portanto, o presente ensaio demonstrará que o campo de incidência dos precedentes é uma questão problemática e pode ter sérias consequências do ponto de vista da resolução de conflitos institucionalizados.

\section{A VINCULATIVIDADE DOS PRECEDENTES}

Precedente judicial consiste em uma decisão pretérita aplicada a casos futuros que possuam identidade quanto às circunstâncias fáticas e jurídicas. A parte do precedente que Ihe confere vinculatividade é chamada de ratio decidendi. Nesse sentido, Cláudia Aparecida Cimardi indica que: 
[...] é necessário que, na realização da atividade do raciocínio elaborado pelo juiz, seja desvendada a parte da decisão anterior que efetivamente deve ser observada com força vinculante. Essa parte da decisão, denominada ratio decidendi (ou holding), pode ser considerada o núcleo do precedente (grifo do autor) (CIMARDI, 2015, p. 43).

Conforme o pensamento de Jean Carlos Dias e Samira Viana Silva, (2017, p. 182), "[a] ratio decidendi é considerada a parte vinculante, obrigatória do precedente, na qual o tribunal apresenta os fundamentos essenciais à decisão e a solução jurídica do caso, que podem ser ligados analogicamente a outros casos". É interessante o entendimento de Hermes Zanetti Jr. acerca do papel das Cortes Supremas na teoria dos precedentes:

A teoria dos precedentes é uma teoria para Cortes Supremas. Isto quer dizer duas coisas: primeiro, que são as Cortes Supremas os principais destinatários de uma teoria dos precedentes por serem cortes de vértice e delas depender a uniformidade da interpretação do direito; segundo, porque também as Cortes Supremas devem ser vinculadas aos próprios precedentes do ponto de vista do ônus argumentativo para afastar a aplicação de um precedente ou superar um precedente antigo na aplicação atual (ZANETTI JÚNIOR, 2017, p. 315).

Este pensamento corrobora o fato de que não somente as instâncias inferiores são vinculadas aos precedentes emanados pelas Cortes Supremas, mas elas próprias, com ainda mais razão, também o são. Isto se deve ao fato de que o respeito das Cortes Supremas aos seus próprios precedentes demonstra que a uniformização de entendimentos - a fim de garantir coerência e integridade ao ordenamento - deve ser levada a sério.

É imperioso destacar que a vinculatividade de um sistema de precedentes não é automática. Sequer na tradição inglesa o precedente "nasceu" vinculante, ou seja, nem o país conhecido por ter uma tradição jurídica marcada por decidir com base em precedentes teve, em sua origem, um sistema de precedentes obrigatórios. Segundo Daniel Mitidiero,

[...] o significado do precedente no direito inglês alterou-se profundamente desde as suas origens medievais até a época contemporânea. Trata-se de evolução que pode ser bem sintetizada em três significativas expressões: ilustração, persuasão e vinculação (grifo do autor) (MITIDIERO, 2017, p. 27).

0 autor (2017, p. 28-30) ensina que desde o medievo os juízes utilizavam precedentes nos casos. Entretanto, o faziam apenas como forma de ilustrar ou explicar o Direito a ser aplicado no caso concreto, o que demonstra, dessa forma, a função ilustrativa do precedente na formação do direito inglês, de modo que todo e qualquer caso era considerado precedente, indistintamente. No entender de Neil Duxbury:

[...] the notion of precedent which existed in the medieval courts was very different from that which was to emerge later. The medieval judicial precedent was, strictly speaking, nothing more than the judgment entered on the plea roll [...] Certainly, a precedent could make an impression on lawyers because it was evidence of common learning, but no single precedent would be accepted as authority in preference to such learning. Indeed although, in the medieval courts, precedents were sometimes treated as evidence of what the law was commonly held to be, the occasional judge or serjeant would 
precedent remark that precedents must not be mistaken for law. ${ }^{3}$ (DUXBURY, 2008 , p. 32-33)

No século XVI, mais especificamente no início da era Tudor (DUXBURY, 2008, p. 33), os precedentes deram outro passo rumo à vinculatividade. Como preleciona Mitidiero (2017, p. 31), os precedentes começaram a desempenhar um papel um pouco mais relevante que outrora no processo de tomada de decisão, passando a servir de critério para decisão do caso - uma vez que não sejam contrários ao Common Law -, alcançando, desse modo, uma função persuasiva, o que marca, com efeito, o início da teoria dos precedentes.

Nesta toada, o precedente judicial passou a ser visto como a evidência da própria existência do Common Law (MITIDIERO, 2017, p. 32). Duxbury (2008, p. 34) assevera que "[t]his subtle shift in emphasis was certainly evident to Coke in his Commentary upon Littleton: 'our book cases are the best proofs what law is ${ }^{4}[$ [...]". Isto é, houve um grande avanço entre as fases de transição acerca da vinculatividade do precedente na Inglaterra, haja vista que antes o precedente não poderia jamais ser confundido com a lei, agora ele passa a ser uma evidência do que ela é.

Muito embora o precedente, na sua fase persuasiva, tenha tido sua relevância para o sistema jurídico inglês, nas palavras de Mitidiero (2017, p. 35) "o precedente persuasivo não chegava a constituir uma norma propriamente dita, na medida em que estava nas mãos dos juízes posteriores, mesmo reconhecendo que o precedente se amoldava ao caso, negar a sua aplicação para a solução do caso". Isto demonstra que o caráter simplesmente persuasivo de um precedente não constitui motivo suficiente para que, contraposto à liberdade interpretativa dos magistrados, faça com que os juízes abandonem sua liberdade de decidir e adotem um precedente não dotado de vinculatividade, muito embora o devessem fazer. De acordo com Cimardi:

Importante notar que a denominada doutrina inglesa do stare decisis não nasceu antes do século XVIII, e, apesar dos diferentes significados que a expressão possa ter, corresponde aos princípios e regras que orientam o uso dos precedentes e seu status de autoridade vinculante (binding precedentes) (CIMARDI, 2015, p. 39).

No século XIX, portanto, o precedente deixou seu caráter persuasivo e efetivamente passou à vinculação, especialmente a partir da influência de Bentham e Austin e com o advento dos Law Reports de 1865 e dos Judcature Acts de 1873-1875 (MITIDIERO, 2017, p. 36). Entretanto, é importante observar que para o sistema de precedentes inglês chegar ao estágio em que se encontra hoje, houve um longo processo que se iniciou no século XIX.

Há somente um caso, datado de 1898, em que todos os Lords da House of Lords disseram em unanimidade que os precedentes da Corte eram vinculantes. E somente em 1966, a partir de um Practice Statment, a Corte entendeu que poderia superar seus precedentes (MITIDIERO, 2017, p. 37).

3 [...] a noção de precedente que existia nas cortes medievais era muito diferente daquela que emergiria mais tarde. 0 precedente judicial medieval era, estritamente falando, nada mais que um julgamento introduzido na plea roll [...] Certamente, um precedente poderia impressionar os advogados porque era uma evidência do conhecimento comum, mas nenhum precedente sequer seria aceito como vinculante em preferência a esse conhecimento. De fato, embora nas cortes medievais os precedentes sejam tratados como evidência do que a lei costumava ser, o juiz ou sargento ocasional observariam pontualmente que precedente não pode ser confundido com lei (tradução nossa).

4 Esta mudança sutil na ênfase foi, certamente, evidente para Coke no seu Comentário sobre Littleton: 'nossos livros de casos são as melhores provas do que o direito é (tradução nossa). 
Tais fatos demonstram que um sistema de precedentes não se consolida rapidamente, são necessárias muitas adaptações e amadurecimento, tanto das Cortes, quanto da sociedade, para entender e aprender a racionar e trabalhar com precedentes, bem como viver uma cultura de valorização do precedente. No caso do Brasil, o primeiro registro de precedente vinculante advém dos assentos portugueses, na época do Brasil Imperial. Após isto, em 1963, através do Ministro Victor Nunes Leal - então Ministro do Supremo Tribunal Federal (STF) -, ocorreu a criação das súmulas de jurisprudência do STF, as quais não possuíam caráter vinculante.

Foram sendo criados, posteriormente, outros instrumentos, sejam processuais ou de jurisdição constitucional, anteriores ao Código de Processo Civil de 2015 (CPC/15), que podem ser considerados como precedentes vinculantes. Dentre estes, estão as decisões provenientes de Ação Direta de Inconstitucionalidade (ADI) e Ação Declaratória de Constitucionalidade (ADC), cuja Lei é de 1999; a súmula vinculante e a repercussão geral em recurso extraordinário, ambos instituídos pela Emenda Constitucional n ${ }^{\circ} 45 / 2004$; o recurso especial repetitivo, que foi inserido no Código de Processo Civil de 1973 através de uma Lei do ano de 2008.

O objetivo do trabalho não é adentrar nos pormenores de tais institutos, contudo, é mister trazer à memória um fato sempre comentado pela doutrina: o $\mathrm{CPC} / 2015$ não trouxe a ideia de precedentes vinculantes pela primeira vez na história processual brasileira recente, o que não afasta o fato de que o novel código deu um grande passo no tocante à sistematização da matéria.

Nas palavras de Ravi Peixoto (2019, p. 138), "[o] CPC/2015 aparece como um consolidador das reformas anteriores para tentar instaurar o stare decisis no direito brasileiro". Tal consolidação ocorreu por meio de uma série de artigos colocados no novo código no sentido de garantir a aplicação dos precedentes e, especialmente, através do art. 927, o qual trata da obrigatoriedade de se observar os precedentes. A previsão contida no art. 927 do CPC/15 é considerada pela doutrina como uma norma fundamental do novo código, muito embora não esteja no rol dos doze primeiros artigos do códex, pois não se trata de rol exaustivo. Posicionam-se nesse sentido, dentre outros autores, Carlos Frederico Bastos Pereira (2018, p. 107-110) e Fredie Didier Jr (2017, p. 71).

Saliente-se que o processo de vinculação formal - ou seja, as alterações legislativas que foram feitas até que se chegasse ao $\mathrm{CPC} / 15$ - representou o primeiro passo no curso das adaptações necessárias para que um sistema brasileiro de precedentes seja consolidado (PEIXOTO, 2019, p. 140). Com efeito, partindo-se do pressuposto de que a vinculatividade é um processo, ou seja, não é algo automático e de que, atualmente, o Brasil passa por uma fase de adaptação a um sistema de precedentes vinculantes e que este é um sistema com suas particularidades, em que medida a vinculatividade dos precedentes influencia ambientes decisórios extrajurisdicionais?

A questão é de extrema relevância, haja vista que a obrigatoriedade atinge, de acordo com a teoria dos precedentes, a Corte que editou o precedente (eficácia horizontal) e os tribunais e juízes inferiores (eficácia vertical). Portanto, tradicionalmente, os efeitos do precedente vinculante irradiam apenas dentro do Judiciário. Mas, e os setores extrajurisdicionais que são afetados por decisões judiciais? Analisar-se-á, a partir de então, a possibilidade de efeito vinculante em ambientes não jurisdicionais. 


\section{O IMPACTO DOS PRECEDENTES NA} ARBITRAGEM DE DIREITO

A relação entre arbitragem e precedentes judiciais é muito espinhosa. Há muito tempo antes da vigência do Código de Processo Civil de 2015 discutia-se sobre se os árbitros estariam vinculados aos precedentes judiciais. Não obstante, com o advento do novo código, a discussão acirrou-se e, atualmente, existem pelo menos três posicionamentos distintos sobre esta matéria.

Existem autores que defendem a total soberania dos árbitros, de modo que os precedentes judiciais não possuem caráter obrigatório em relação à arbitragem. Outros autores, diferentemente, adotam uma posição mista, defendendo a vinculação dos árbitros apenas às súmulas vinculantes e decisões do Supremo Tribunal Federal em controle concentrado. Por outro lado, há os que defendem a sujeição dos árbitros aos precedentes.

Rômulo Greff Mariani (2018, p. 37) entende que a jurisdição, enquanto meio de pacificação social, pode ser exercida tanto pelo juiz quanto pelo árbitro. 0 autor aduz que tal atividade passou a ser efetivamente reconhecida e que muito embora a atividade jurisdicional seja típica do Judiciário, não Ihe é exclusiva. Ademais, o referido autor entende que "a arbitragem prestará jurisdição de forma análoga ao que ocorreria caso as partes tivessem buscado o judiciário estatal, no que se assemelham, haja vista ser a arbitragem, também, um mecanismo que proclama o direito" (MARIANI, 2018, p. 38-39).

Em conformidade com o pensamento de Mariani (2018, p. 75), o processo arbitral e o processo judicial têm em comum a sua natureza "resolutória de conflitos", ou seja, ambos buscam a pacificação dos litígios através de um caminho organizado, de modo que as prerrogativas e garantias das partes sejam respeitadas. Entretanto, em que pese essa similaridade, não se confundem. No entender de Ricardo Dalmaso Marques, pode-se estabelecer três premissas principais no que tange à arbitragem:

[...] é importante que se estabeleçam as premissas de que (i) o instituto da arbitragem (de uma forma geral, no âmbito internacional, e não apenas como estabelecido na legislação brasileira pela Lei no 9.307/1996 consiste em um sistema específico, com regras próprias, e marcado, precipuamente, pela flexibilidade procedimental e pela autonomia da vontade concedida às partes quanto às leis que devem ser aplicadas; (ii) entre essas regras próprias, as de criação e aplicação de precedentes ou da jurisprudência (judiciais ou arbitrais) também possuem, na arbitragem, nuances bastante diversas daquelas aplicáveis na esfera judicial, e (iii) os ritos processual e procedimental (o que inclui o procedimento recursal, baseado na hierarquia, e as ferramentas e remédios eminentemente processuais) existentes no âmbito do Poder Judiciário não se estendem à arbitragem, porquanto, de forma diversa, possui mecanismos próprios - e, consequentemente, requisitos e hipóteses específicos - para impugnação da sentença arbitral (MARQUES, 2013, p. 8).

O entendimento de Dalmaso Marques (2013, p. 9) é no sentido de que quando se elege a arbitragem enquanto sistema processual a ser aplicado ao caso concreto, renuncia-se ao sistema processual estatal e a análise do mérito pelo Poder Judiciário, de modo que isto implica na renúncia, também, das regras e ferramentas processuais que são inerentes ao sistema judicial e que, portanto, não se estenderiam ao arbitral. Na perspectiva de Mariani 
(2018, p. 76-87), o processo arbitral seria um subsistema autônomo em relação ao processo estatal e com base nisto, destaca três conclusões principais: o Código de Processo Civil não se aplica ao processo arbitral, os precedentes judiciais também não se aplicam ao processo arbitral e o árbitro é soberano em suas decisões:

Como consequência lógica, é possível fixar uma regra geral de que não estão os agentes envolvidos na arbitragem submetidos a institutos próprios do processo estatal, notadamente para o que aqui mais importa, às técnicas de julgamento e vinculação estabelecidas no diploma processual estatal, de forma que esses "precedentes" não vinculam o árbitro. As previsões contidas no atual Código de Processo Civil, via de regra, não se aplicam, mesmo que de forma complementar ou subsidiária, ao processo arbitral, exceto se assim as partes convencionarem ou mesmo dessa forma prever o regulamento aplicável ao processo arbitral (o que não é recomendado) (MARIANI, 2018, p. 87).

Para o autor, apontar que o árbitro é soberano na aplicação do Direito significa dizer que o mesmo não se vincula à visão do Judiciário estatal, pois inclusive no Direito Inglês, o Arbitration Act Inglês foi motivado pelo fato de que a arbitragem não é um anexo do Judiciário estatal (MARIANI, 2018, p. 88). Contudo, o precedente, enquanto técnica de uniformização de jurisprudência, acaba por expressar a visão sobre a aplicação em concreto do Direito estatal, visão a qual o árbitro pode não concordar e caso não concorde, estará aplicando o direito, mesmo que não da mesma forma que o juiz estatal e será soberano para sustentar essa posição (MARIANI, 2018, p. 88-89).

Inclusive, o autor assevera que o anseio por coerência e integridade ${ }^{5}$ na aplicação do direito determinariam a necessária adoção pelo árbitro dos precedentes, o que, em sua visão, subverteria, a lógica da arbitragem por ser um avanço indevido em relação à autonomia do árbitro, o qual exerce sua função perante as partes e não perante a sociedade. Logo, ele não teria o dever de salvaguardar a integridade ou a coerência da ordem jurídica, demonstrando, assim, que a relação do árbitro com o direito é diferente da relação do juiz com o direito (MARIANI, 2018, p. 90).

Portanto, segundo o autor (2018, p. 91), não há que se falar em vinculatividade dos precedentes judiciais no processo arbitral, porque a lei processual não encontra guarida no processo arbitral (nem sequer subsidiariamente) e devido ao fato de os árbitros serem soberanos. Dessa forma, o precedente judicial, em relação às decisões arbitrais teria meramente efeito persuasivo, não devido a uma interferência indevida do dos precedentes judiciais e do Judiciário no âmbito da arbitragem, mas tendo em vista uma influência persuasiva natural que os precedentes possuem (MARIANI, 2018, p. 94). Nas palavras do referido autor:

Assim, pode haver na decisão pretérita estatal um efeito persuasivo, e é natural que assim seja. [...] Aflora aqui a já mencionada autoridade de que as decisões pretéritas gozam, com maior ou menor vigor a depender de alguns elementos, como a qualidade das razões trazidas pela decisão. E isso é algo que não se pode controlar. Se as partes pautam sua conduta, se os advogados fazem uso para construir o seu caso e se os árbitros podem, em tese, se deixar influenciar pelo julgado estatal, nada há que se possa fazer para evitar isso (MARIANI, 2018, p. 94).

5 Com o CPC/15, coerência e integridade não são somente anseios, mas passam a ser verdadeiros princípios norteadores do código, previstos no art. 926. 
Marcos Serra Netto Fioravanti (2017), por outro lado, assume uma posição mista diante da problemática. Para o autor, as súmulas vinculantes possuem observância obrigatória pelos árbitros, assim como devem ser observadas todas as fontes do direito escolhidas pelas partes por ocasião da eleição da arbitragem, de modo que os verbetes sumulares não podem ser ignorados ou contrariados pelos árbitros sem que seja feita distinção (FIORAVANTI, 2017, p. 82).

Além disso, o autor defende que as decisões do Supremo Tribunal Federal em controle concentrado de constitucionalidade são de observância obrigatória pelos árbitros, já que possuem efeito erga omnes e eficácia vinculante. Dessa forma, os árbitros devem aplicá-las como forma de decidir em conformidade com a ordem jurídica brasileira, como esperam as partes que elegeram a arbitragem (FIORAVANTI, 2017, p. 91).

Todavia, quanto às demais espécies de precedentes constantes no art. 927 do CPC/15, o autor é enfático ao declarar a não vinculação dos árbitros a tais precedentes. Ele defende a vinculação dos árbitros às súmulas vinculantes e às decisões do STF em controle concentrado devido à integridade do sistema normativo e a convenção arbitral, e não, conforme ele, a equivocada ideia de aplicação do Código de Processo Civil ao processo arbitral, de modo que as demais hipóteses do art. 927 do CPC/15 não são de observância obrigatória pelos árbitros (FIORAVANTI, 2017, p. 96).

Tal posição, assim, assume que entre os precedentes, como sistematizados no atual Código de Processo Civil, existem graus distintos de vinculatividade, sendo obrigatórios apenas os decorrentes da jurisdição constitucional. Os argumentos suscitados pelo autor, de certo modo, refutam a ideia defendida pela corrente da inaplicabilidade dos precedentes, mas carece de uma fundamentação mais profunda derivada da própria Teoria do Direito, que, como será demonstrado adiante, não poderia assumir a existência de sistemas normativos concorrentes e incompatíveis.

\section{O IMPACTO DOS PRECEDENTES NA REGULAÇÁO DE SERVIÇOS PÚBLICOS}

As agências reguladoras são consideradas autarquias especiais, tendo em vista a certas peculiaridades que possuem, como a autonomia decisória, a qual significa que as referidas autarquias têm ampla autonomia para decidir questões administrativas que envolvam os agentes regulados, bem como os usuários do serviço por ela regulado. Isto é, as agências reguladoras detém poder revisional de seus atos em última instância administrativa (CARVALHO FILHO, 2018, p. 577).

Muito embora a autonomia decisória dessas autarquias, nada impede que os concessionários, permissionários ou autorizados à prestação de serviços públicos, em caso de discordância da decisão administrativa, ingressem no Judiciário com ação contra estes atos administrativos, especialmente se forem contra o ordenamento jurídico, seja em dissonância com a lei ou os precedentes. $\mathrm{E}$, se tais atos atingirem um grande número de envolvidos, especialmente os usuários do serviço, é totalmente possível que seja instaurado um Incidente 
de Resolução de Demandas Repetitivas (IRDR), caso todos os requisitos autorizadores da instauração sejam cumpridos.

Neste tocante, a grande discussão gira em torno do art. $985, \S 2^{\circ}$, do $\mathrm{CPC} / 15$, o qual trata da relação entre precedentes e agências reguladoras. 0 mencionado artigo preceitua que quando a tese adotada no resultado do julgamento do IRDR tratar sobre a prestação de serviço concedido, permitido ou autorizado, a decisão será comunicada ao órgão, ente ou agência reguladora responsável pela fiscalização da efetiva aplicação.

André Guskow Cardoso (2016, p. 12-15) aduz que a ratio legis seria no sentido de que a comunicação da qual o citado dispositivo legal menciona não se referiria a um comando, ordem ou determinação às agências reguladoras. Para o autor, trata-se, diferentemente, de uma comunicação para que tais agências tomem conhecimento da tese adotada no âmbito do IRDR, de modo que tal decisão não teria efeito vinculante em relação às agências reguladoras.

Outro argumento contrário à incidência dos precedentes em relação às agências reguladoras é o argumento da inconstitucionalidade do art. $985, \S 2^{\circ}$, do $\mathrm{CPC} / 15$, o qual está sendo discutido na ADI 5492, proposta pelo Estado do Rio de Janeiro em 2016. Weber Luiz de Oliveira (2019, p. 163) trata da Lei das Agências Reguladoras (Lei Federal n 13.848/2019), a qual, em seu art. $6^{\circ}$, dispõe que a alteração de atos normativos de interesse geral dos agentes econômicos, consumidores ou usuários dos serviços prestados deve ser precedida da realização de Análise de Impacto Regulatório (AIR).

Oliveira (2019, p. 164), então, afirma a impossibilidade de se impor, por intermédio da via jurisdicional, as teses adotadas em julgamento de casos repetitivos às agências reguladoras sem que se realize o AIR previamente. Além deste argumento, o autor afirma que o Código de Processo Civil usurpa a competência constitucional definida no art. 175, parágrafo único, inciso I, da Constituição Federal, bem como no art. 174 da Carta Magna, de modo a macular o princípio da separação dos poderes.

Isto significa que, segundo o autor, a lei processual civil não teria o condão de atribuir a decisão judicial como se daria a forma de atuação das agências reguladoras, pois somente lei específica poderia fazê-lo (OLIVEIRA, 2019, p. 167). No entanto, o entendimento de ambos os autores possuem inconsistências. Inicialmente, cumpre esclarecer que o disposto no art. $985, \S 2^{\circ}$, do Código de Processo Civil não se refere a uma mera comunicação a ser feita às agências reguladoras. Pelo contrário. 0 artigo faz a seguinte menção: "agência reguladora competente para fiscalização da efetiva aplicação" (BRASIL, 2015).

Isto significa que a agência reguladora será sim comunicada, mas para que ela efetivamente aplique o entendimento veiculado na decisão que firmou tese em sede de IRDR. Ou seja, ela será comunicada para aplicar entendimento ao qual está vinculada, porque tem que fiscalizar efetivamente a aplicação do entendimento adotado na decisão.

Outrossim, acerca do argumento de necessidade de prévia realização do AIR, é essencial elucidar que tal argumento é inconsistente em termos sistemáticos e, assim, práticos. Primeiramente, importa dizer que 0 art. $6^{\circ}$ da Lei Federal $n^{\circ} 13.848 / 2019$ afirma que caso haja proposta de alteração de ato normativo de interesse geral, isto deverá ser precedido de AIR. Ato normativo ao qual o dispositivo se refere são todos os atos normativos feitos pelas próprias agências reguladoras, em seu poder regulamentar. Estendendo o argumento, a suges- 
tão seria a de submeter as decisões judiciais a um juízo de conveniência e oportunidade o que, obviamente, é incompatível com o primado do Estado de Direito. Além disso,

No tocante ao argumento da separação dos poderes, há consolidado entendimento compartilhado nos estudos contemporâneos de que o controle judicial é cabível quando se tratam de questões em que estão em debate os direitos fundamentais, essencialmente os atendidos pelos serviços públicos. Tal nível de revisão judicial se tornou cotidiana, atendendo a temas que vão da concretização do direito à saúde, passado pelo direito à educação e, mesmo, alcançado direitos de natureza social. A esse respeito Dias, em estudo específico, apontou:

Vale dizer que o controle judicial constitui-se numa técnica bastante efetiva de arranjo institucional, na qual o Poder Judiciário assume a guarda da Constituição, podendo exercer essa função de modo a opô-la ao Poder Executivo e ao Poder Legislativo. Já demonstramos que a atuação das Cortes não representa em si mesma uma violação ao princípio democrático, mas sim um verdadeiro modo de sua garantia a partir da proteção aos cidadãos que para aquele fim democrático concorrem e interagem. 0 controle judicial está intimamente relacionado a uma Democracia Constitucional. Uma vez que uma sociedade estrutura-se sob a forma de um Estado de Direito, a linha de condução política é a submissão à proteção dos direitos fundamentais. 0 controle do comportamento político variante é, portanto, uma consequência absolutamente lógica daquele sistema. (DIAS, 2016, p. 190).

Logo, a visão contemporânea das relações de controle entre as funções estatais, em nada, é incompatível com a atuação judicial de edição de precedentes que tenham de ser incorporados, obrigatoriamente, à pauta regulatória das agências reguladoras. Vale dizer que a formulação de precedente é derivada da solução de um conflito jurisdicional que, por isso, está na área de atuação própria do Poder Judiciário, contudo, diante da natureza fundamental deve ser reforçada pelas demais funções estatais.

Cumpre lembrar que o IRDR tem como como requisitos multiplicidade de demandas (real ou potencial), que não haja necessidade de instrução probatória, assim como demonstração de que se houver tratamento diferente, haverá quebra à isonomia e segurança jurídica. Portanto, caso haja uma questão de massa que verse sobre serviço concedido, permitido ou autorizado, mas a questão cumpra os requisitos, pode ser instaurado o IRDR. Inclusive, é necessário que seja instaurado para que haja uniformização do entendimento e para que a própria agência reguladora adote um único entendimento.

Caso a agência reguladora entenda que a decisão que firmou tese no IRDR é equivocada, pode recorrer às Cortes Superiores. Entretanto, conforme o entendimento de Lucas Gil Carneiro Salim, a vinculação das agências reguladoras aos precedentes se mostra essencial, pois deve-se abrir o diálogo entre o Judiciário e as agências reguladoras, a fim de evitar as ações e, quiçá, aumentar a eficiência do órgão jurisdicional. Veja-se:

Como ficou demonstrado anteriormente, no Relatório do CNJ, "100 maiores litigantes", 24\% dos 100 milhões de processos analisados referem-se a empresas de telefonia e concessionárias de serviços públicos. Nesses termos, é fundamental que seja aberto o diálogo entre o Poder Judiciário e as agências reguladoras, justamente para que seja evitada a litigância de massa, quando as questões possam ser decididas em âmbito administrativo interno das entidades fiscalizadoras. (SALIM, 2015, p. 11). 
Deste modo, é inegável que o entendimento segundo o qual as agências reguladoras são vinculadas aos precedentes é o mais acertado, haja vista a observância de algo muito caro ao Código de Processo Civil de 2015 e a toda ordem jurídica: a uniformização de entendimentos.

\section{O IMPACTO DOS PRECEDENTES PERANTE OS ÓRGÃOS PARAJURISDICIONAIS}

Órgãos parajurisdicionais, em sentido lato, são unidades administrativas apartadas do Judiciário e do Legislativo. Para os fins deste trabalho, utiliza-se o termo "parajurisdicional" especificamente para caracterizar órgãos administrativos competentes para julgar - administrativamente - recursos.

Neste artigo, diante da multiplicidade de órgãos com tais funções, será examinada a relação dos precedentes judiciais com o processo de decisão do Conselho Administrativo de Recursos Fiscais (CARF), que, contudo, pode ser amplamente extrapolada para outras instâncias administrativas. Antes de adentrar propriamente na relação dos precedentes com o CARF, é interessante explicitar o entendimento esposado por Weber Luiz de Oliveira acerca da aplicação dos precedentes na Administração Pública.

Segundo Oliveira (2019, p. 232-234), apenas os precedentes previstos no art. 927 do CPC/15 são aplicáveis à Administração Pública. Entretanto, o autor faz uma diferenciação desnecessária entre precedentes diretamente e indiretamente vinculantes. Para o referido doutrinador, os precedentes diretamente vinculantes são apenas a súmula vinculante e as decisões em controle concentrado, haja vista que há autorização constitucional para que sejam aplicados em relação à Administração Pública.

Os indiretamente vinculantes, por outro lado, são os restantes, os quais dependeriam da edição de uma lei autorizativa, ou seja, deveria ser editada lei que permitisse a aplicação dos demais precedentes à Administração Pública. Tal posicionamento é equivocado.

Primeiramente, não se deve fazer diferenciação entre os precedentes, como se uns tivessem maior força que os outros. Além disso, deve-se estabelecer uma interpretação sistemática em relação ao sistema de precedentes. As ações de controle concentrado e a súmula vinculante foram criadas, respectivamente, em 1999 e 2004, momento no qual ainda não havia sido pensado todo um sistema de precedentes.

Tal ideia foi amadurecendo com o passar dos anos e foram sendo introduzidos outros tipos de precedentes, gradativamente, como demonstrado no segundo tópico. Com o advento do Código de Processo Civil de 2015, tal sistema foi implementado. Portanto, a leitura sistemática seria no sentido de interpretar, à luz da Constituição Federal, os demais precedentes como também vinculantes à Administração Pública.

Não se tem agora apenas dois tipos de precedente, tem-se vários, de igual peso das súmulas e das decisões de controle concentrado, e que devem ser interpretados como vinculantes em relação à Administração Pública. Inclusive, o CARF, em seu regimento interno, prevê no art. 62 que os conselheiros do CARF não podem afastar entendimento de tratado, 
acordo internacional, lei ou decreto sob alegação de inconstitucionalidade, exceto se um destes atos normativos fundamentar crédito tributário objeto de súmula vinculante ou decisão do Superior Tribunal de Justiça (STJ) ou Supremo Tribunal Federal (STF) em recursos repetitivos.

Tal previsão é tão séria que é amparada pelo art. 45 do referido regimento, segundo o qual o conselheiro que descumprir o disposto no art. 62, poderá perder o mandato. Ademais, há a previsão no art. 80 de que as decisões proferidas em desacordo com súmula vinculante ou decisão do STJ ou STF em recursos repetitivos são nulas. Todavia, conforme as lições de Cassiano Menke, existem dois tipos de força normativa, uma formal e uma material:

Força normativa formal consiste no efeito vinculante do qual o precedente é dotado em decorrência de expressa disposição legal. Trata-se das situações em que enunciados normativos estabelecem vinculação de certo órgão aos precedentes. Exemplo dessa vinculatividade formal está no art. 62 do Regimento Interno do CARF. Veja-se que, nas hipóteses arroladas pelo aludido dispositivo, é devido aos membros do CARF seguirem os precedentes judiciais. Força normativa material, por outro lado, decorre do conteúdo da decisão e do seu órgão prolator (ÁVILA, 2014b, p. 498). A vinculatividade do precedente, nesse caso, advém da pretensão de permanência e da definitividade que essas decisões apresentam. Isso em razão de terem conteúdo capaz de ser universalizado para solução de casos semelhantes. Advém, igualmente, da circunstância de terem sido proferidas por cortes supremas a quem cabe, segundo a $\mathrm{CF} / 88$, dar a última palavra em determinadas matérias (MENKE, 2018, p. 93).

Segundo o autor, na maioria das decisões do CARF, admite-se apenas a força normativa formal, isto é, o CARF entende estar vinculado apenas nas hipóteses previstas no art. 62 do Regimento Interno do Conselho Administrativo de Recursos Fiscais (RICARF), de modo que não teria o dever de adotar outros tipos de precedentes. Egon Bockmann Moreira afirma peremptoriamente que não se pode mais proferir decisões administrativas dissonantes da jurisprudência:

Assim, já se passou o tempo em que se poderia cogitar de prestígio a decisões administrativas em desrespeito à jurisprudência. Tal obrigação de conhecimento e obediência é cogente e se exterioriza sob diversos ângulos. Por um lado, há o dever de "uniformizar sua jurisprudência e mantê-la estável, íntegra e coerente" (art. 926). Esse dispositivo é de alta relevância no processo administrativo: em havendo Tribunais administrativos, aplica-se a regra cogente de uniformização (qualidade de algo que não varia nem na forma nem no conteúdo), estabilização (firmeza, solidez, constância e previsibilidade), integridade (manutenção de sua plenitude, sem agressões) e coerência (coesão, compreensibilidade e respeito às consequências) das decisões colegiadas (grifo do autor) (MOREIRA, 2016, p. 321).

Outrossim, o autor (2016) demonstra que os deveres contidos no art. 926 do CPC/15 visam preservar o princípio da segurança jurídica e que os Tribunais, inclusive os administrativos, devem preservar sua jurisprudência, haja vista que isto é uma forma, também, de garantir estabilidade interna, de modo a chegar-se num patamar de redução de custos processuais, como tempo, volume de processos e recursos, etc. E conclui asseverando que:

Logo, a todos os órgãos e entidades administrativas equivalentes a Tribunais - rectius: colegiados decisórios -, sem exceção, desde os Tribunais de Contas até o Conselho Nacional de Justiça (CNJ), passando pelo Conselho 
Administrativo de Defesa Econômica (Cade), bem como conselhos de contribuintes, corregedorias e agências reguladoras, foi atribuído o dever processual de prestigiar a segurança jurídica advinda da estabilidade de decisões anteriores, que precisam se tornar uniformes com o decorrer do tempo (a mesma forma e o mesmo conteúdo decisório) (grifo do autor) (MOREIRA, 2016, p. 322-323).

Por conseguinte, tendo em vista o princípio da segurança jurídica, os precedentes contidos no art. 927 do CPC/15 devem ser aplicados pela Administração Pública, especialmente pelos Tribunais Administrativos. Trata-se de uma aplicação extremamente necessária, a fim de que haja uma coerência de entendimentos entre o Poder Judiciário e os referidos tribunais, para que as controvérsias sejam resolvidas, de pronto, nos Tribunais Administrativos, com vistas a evitar o ajuizamento de novas demandas.

\section{POR UMA ABORDAGEM SISTEMÁTICA DAS NORMAS JURÍDICAS DERIVADAS DE PRECEDENTES.}

O atual estágio da Teoria do Direito pugna por uma visão compreensiva do fenômeno jurídico, tanto quanto possível, buscando uma uniformidade no reconhecimento das normas e de sua aplicação. Enfoques profundamente distintos assumem a perspectiva integrativa ao estabelecer critérios que selecionam as normas que, sendo jurídicas, devem ser consideradas obrigatórias, e, por isso, ser aplicadas por todos os órgãos dotados de autoridade.

Embora não se possa aqui sintetizar todas as possíveis variáveis teóricas, uma exposição ilustrativa pode ser adequada para demonstrar que qualquer concepção do Direito contemporâneo apoiaria uma compreensão uniforme das normas derivadas de precedentes. É nesse sentido que Dworkin, numa visão não positivista, exige que as soluções construídas pelos aplicadores devam ser íntegras, levando em consideração o histórico argumentativo do tema, sob pena de serem consideradas ilegítimas. Nesse sentido, Dias ensina:

É nesse sentido que Porto Macedo aponta: "Para Dworkin, a interpretação do direito significa ver o direito como um corpo coerente, integrado e articulado a uma intencionalidade (que não se confunde com a intenção dos legisladores). Para ele, a descrição da dimensão da normatividade do direito pressupõe e requer a incorporação de uma dimensão interpretativa". Isso explica porque a correção de uma resposta é teoricamente possível dentro de uma proposta que rejeita critérios externos de correção e exige que as definições conceituais e sua articulação prática dependam de uma prática interpretativa concebida de tal forma que a devida contextualização leve a respostas corretas (DIAS, 2019, p. 98).

Logo, sendo um corpo normativo integrado, não podem existir decisões que reconheçam direitos em um âmbito e, simultaneamente, os neguem em outro. No âmbito do pensamento dworkiniano não se pode chamar de Direito um tal sistema.

No âmbito extremo, a dos positivistas exclusivos, igualmente a definição do ordenamento jurídico depende de um sistema de reconhecimento que confere unidade ao Direito, nesse exato sentido, mesmo sob uma abordagem positivista, não se poderia admitir a con- 
vivência de padrões de decisão parcialmente vigentes. Nesse sentido Dias (2019, p. 148), ao analisar o pensamento da Joseph Raz, aponta:

Raz, porém, enfatiza que a chave para a identificação de um sistema institucionalizado não está na investigação sobre os órgãos que criam as normas, mas naqueles que as aplicam, pois eles é que indicam quais normas estão efetivamente em vigor. Neste particular, em especial, o objetivo é refutar a tese da centralidade da fonte normativa no plano legislativo e justificar a multiplicidade de regras de reconhecimento. Esses órgãos de aplicação são decisivos para a caracterização de um sistema de normas como institucional, pois eles garantem a unidade do sistema, uma vez que: a) estabelecem os padrões individuais de conduta; b) aplicam as normas já existentes; c) exercem determinações vinculantes, isto é, que devem ser obedecidas independentemente da anuência do destinatário (DIAS, 2019, p. 148).

O contraponto acima feito, entre extremos da atual Teoria do Direito, não exclui o fato de que outras teorias concorrentes, partindo de premissas distintas e formulações próprias, de modo algum, admitem a possibilidade de coexistência de normas cogentes e não cogentes sobre o mesmo direito. Ainda que em nenhum dos campos de incidência antes apresentados exista unanimidade de entendimento, uma abordagem a partir da Teoria do Direito sugere que não se possam admitir uma incidência parcial ou não incidência dos precedentes nos ambientes decisórios examinados.

\section{CONCLUSÃO}

Diante dos diversos posicionamentos expostos, verifica-se que o tema abordado não é pacífico. Contudo, o entendimento mais acertado acerca da questão principal que perpassa por este artigo é aquele segundo o qual os precedentes são obrigatórios não somente no âmbito jurisdicional, mas também para a Administração Pública, seja para órgãos parajurisdicionais, como o CARF, seja para agências reguladoras, especialmente no caso previsto no art. $985, \S^{\circ}$, do $\mathrm{CPC} / 15$, além de serem vinculativos para os árbitros.

Deste modo, Tribunais Administrativos, agências reguladoras e árbitros estão sujeitos aos precedentes judiciais em decorrência de princípios basilares do nosso ordenamento jurídico, como da segurança jurídica e isonomia. Contudo, não somente o respeito a tais princípios leva à conclusão inarredável de que os precedentes judiciais são vinculantes em ambientes não jurisdicionais, mas, em especial, a partir de uma análise de diferentes posições dentro da Teoria do Direito, as quais apontam para uma integridade (Ronald Dworkin) ou unidade (Joseph Raz) do Direito, de modo que não se admite a existência concomitante de posicionamentos diametralmente opostos em relação a um mesmo direito.

No tocante à Administração Pública, caso os precedentes judiciais fossem efetivamente adotados e o entendimento de que estes são vinculantes prevalecesse, haveria maior segurança jurídica e estabilidade entre as decisões do Judiciário e da Administração Pública, sem que isto representasse uma afronta à separação dos poderes, porque o entendimento aplicado não seria um comando do Judiciário ao Executivo, mas sim a aplicação do direito vigente, de maneira uniforme, em ambas as esferas. 
0 árbitro, por sua vez, continua sendo soberano nos termos da convenção de arbitragem, mas ele deve se vincular aos precedentes judiciais justamente por uma questão de coerência sistêmica, pois ele não pode decidir em sentido contrário ao direito, ignorando os precedentes que se tornaram, ao longo dos anos, fonte primária do direito.

As agências reguladoras, por outro lado, continuam sendo dotadas de autonomia decisória, enquanto autarquias em regime especial. A vinculação dos precedentes em relação às agências reguladoras não significa a retirada desta autonomia. Diferentemente, representa a compatibilização dos atos administrativos e normativos dessas agências em relação à lei e aos precedentes, pois a finalidade última do art. $985, \S 2^{\circ}$, do $\mathrm{CPC} / 15$ é o aprimoramento da prestação de serviços públicos e da própria regulação destes, a fim de melhor garantir os direitos dos usuários.

Para que essa vinculatividade ocorra no âmbito extrajurisdicional é necessário, entretanto, que como dito no segundo tópico, o sistema de precedentes brasileiro continue passando por seu processo de adaptação, visto que muitos ajustes são ainda necessários.

\section{REFERÊNCIAS}

BRASIL, Código de Processo Civil. Vade Mecum. 4ª Ed. Salvador: Juspodivm, 2018.

CARDOSO, André Guskow. O Incidente de Resolução de Demandas Repetitivas - IRDR e os serviços permitidos, concedidos ou autorizados. Disponível em http://www.mpsp.mp.br/portal/page/portal/documentacao_e_divulgacao/doc_biblioteca/bibli_servicos_produtos/bibli_boletim/bibli_bol_2006/RDAdmCont_n.23.06.PDF. Acesso em: 23 nov. 2019.

CARVALHO FILHO, José dos Santos. Manual de Direito Administrativo. São Paulo: Atlas, 2018.

CIMARDI, Cláudia Aparecida. A Jurisprudência Uniforme e os Precedentes no Novo Código de Processo Civil Brasileiro. São Paulo: Revista dos Tribunais, 2015.

DIAS, Jean Carlos. O Controle Judicial de Políticas Públicas. 2a ed. Salvador: Juspodivm, 2016.

DIAS, Jean Carlos; SILVA, Samira Viana. O Direito Sumular Brasileiro: Uma Abordagem Crítica à Luz da Teoria dos Precedentes e da Análise Econômica do Direito. In: DIAS, Jean Carlos; BRITO FILHO, José Cláudio Monteiro de; MOUTA, José Henrique (Org). Concretização dos Direitos Fundamentais e Sua Fundamentação: Abordagens a partir da teoria do processo, da análise econômica do direito e das teorias da justiça. Rio de Janeiro: Lumen Juris, 2017.

DIAS, Jean Carlos. Teorias Contemporâneas do Direito e da Justiça. 2ª . Ed. Salvador: Juspodivm, 2019.

DIDIER JR, Fredie. Curso de Direito Processual Civil: Introdução ao Direito Processual Civil, Parte Geral e Processo de Conhecimento. 19ª Ed. Salvador: Juspodivm, 2017.

DUXBURY, Neil. The Nature and Authority of Precedent. Cambridge: Cambridge University Press, 2008.

FIORAVANTI, Marcos Serra Netto. A Arbitragem e os Precedentes Judiciais: Observância, Respeito ou Vinculação? 2017. 137 f. Dissertação apresentada no Programa de Pós-Graduação em Direito, Pontifícia Universidade Católica de São Paulo. 2017.

MARIANI, Rômulo Greff. Precedentes na Arbitragem. Belo Horizonte: Fórum, 2018.

MARQUES, Ricardo Dalmaso. Inexistência de Vinculação do Árbitro às Decisões e Súmulas Vinculantes do Supremo Tribunal Federal. Disponível em: https://www.academia.edu/38532293/Inexistência_de_vinculação_ do_árbitro_às_decisões_e_súmulas_judiciais_vinculantes_do_Supremo_Tribunal_Federal. Acesso em: 05 nov. 2019. 
MENKE, Cassiano. 0 dever de fundamentação estabelecido no art. 489, $\S 1^{\circ}$, do Código de Processo Civil: um novo paradigma de conhecimento e aplicação do direito e alguns dos seus impactos no processo administrativo fiscal. In: GOMES, Marcos Lívio; Oliveira, Francisco Marconi de. Estudos Tributários e Aduaneiros do III Seminário CARF. Disponível em: http://idg.carf.fazenda.gov.br/publicacoes/estudos-tributarios-e-aduaneiros-do-iii-seminario-carf.pdf. Acesso em: 07 de nov. De 2019.

MITIDIERO, Daniel. Precedentes: da persuasão à vinculação. 2ª Ed. São Paulo: Revista dos Tribunais, 2017.

MOREIRA, Egon Bockmann. O Novo Código de Processo Civil e sua aplicação no Processo Administrativo. Disponível em: https://bibliotecadigital.fgv.br/dspace/handle/10438/27009. Acesso em: 07 de nov. 2019.

OLIVEIRA, Weber Luiz. Precedentes Judiciais na Administração Pública: Limites e possibilidades de aplicação. $2^{\mathrm{a}}$ Ed. Salvador: Juspodivm, 2019.

PEIXOTO, Ravi. Superação do Precedente e Segurança Jurídica. 4ª Ed. Salvador: Juspodivm, 2019.

PEREIRA, Carlos Frederico Bastos. Norma Fundamental do Processo Civil Brasileiro: Aspectos Conceituais, Estruturais e Funcionais. Civil Procedure Review: Munique, vol. 9, n. 1, p. 107-110, jan./apr. 2018.

SALIM, Lucas Gil Carneiro. A Aplicação da Teoria dos Precedentes na Administração Pública. Disponível em: http://www.periodicos.ufes.br/?journal=ppgdir-semanajuridica\&page=article\&op=view\&path[]=12806. Acesso em: 07 nov. 2019.

ZANETTI JR, Hermes. O valor vinculante dos precedentes. $3^{a}$ Ed. Salvador: Juspodivm, 2017.

Recebido/Received: 09.05.2020.

Aprovado/Approved: 04.06 .2020 